\title{
Matéria Orgânica e nutrientes na mata de terra firme perto de Manaus
}

\author{
H. KLINGE $(*)$ \\ WILLIAM A. RODRIGUES("⿻)
}

\section{I - DADOS PRELIMINARES}

Em continuação aos nossos estudos sôbre vegetação e solos da área de Manaus (Altemuller \& Klinge, 1964; Klinge, 1962, 1965 , 1967; Klinge \& Ohle, 1964; Sioli \& Klinge, 1962, 1966; Rodrigues, 1967) fizemos de junho a novembro de 1970 o estucio de uma mata de terra firme sôbre latosol argiloso localizada no $\mathrm{Km} .64$ da Estrada Manaus Itacoatiara num terreno plano e adjacente à Reserva Florestal Walter Egler do I.N.P.A. (porém no sítio de propriedade do Prof. F. N. Souza), onde em 1963/64 medimos a produção de manta vegetal (Klinge \& Rodrigues, 1968 a, b) .

A área de estudo tinha a dimensão de $2.000 \mathrm{~m}^{2}(40 \times 50 \mathrm{~m})$, sendo subdividida em 8 faixas de $50 \mathrm{~m}$ de comprimento por $5 \mathrm{~m}$ de largura e cada uma destas subdividida em 5 parcelas iguais.

Em cada parcela colhíamos e pesávamos tôdas as plastas menores a $1,5 \mathrm{~m}$ de altura; em algumas parcelas contávamos o número de indivícuos; em qualquer dos casos agrupávamos as plantas em 4 classes de altura:

$<20 \mathrm{~cm}, 20-50 \mathrm{~cm}, 50-100 \mathrm{~cm}, 100-150 \mathrm{~cm}$; separávamos as fôlhas e raizes do caule mais raminhos e novamente tirávamos amostras pesadas de cada fração para análise química posterior.

Depois de limpa assim a área de estudo, contávamos e numerávamos tôdas as plantas acima de $1,5 \mathrm{~m}$ de altura; também medíamos as suas distâncias das linhas marginais das parcelas; medíamos a altura total, compri. mento do caule, diâmetro da copa e diâmetro do caule à altura do peito durante o inventário ou após a derruba das árvores.

Coletamos detritos orgânicos na superfície do solo dentro de uma área de $0,25 \mathrm{~m}^{2}$ cada uma em 10 lugares em tôrno da área de estudo, quando iniciamos o estudo; em 5 dêsses lugares colocamos caixas coletoras de $50 \times 50 \mathrm{~cm}$ para medir semanalmente a produção de manta vegetal. No final do estudo, tiramos amostras de solo dentro dos limites da área de estudo, sob uma superfície cada uma de $50 \mathrm{x} 50 \mathrm{~cm}$ e mais para baixo até cêrca de $1,10 \mathrm{~m}$ de profundidade, em 5 pontos diferentes; em 5 outros lugares tiramos amostras apenas de detritos orgânicos da superfície do solo numa área cada uma de $0,25 \mathrm{~m}^{2}$. Nas covas abertas no solo apanhávamos as raizes tão inteiras quanto possíveis, à mão; os dados de massa radicular e comprimento de raiz serão comparados posteriormente com os de um podsol humoso profundo de uma "campina" situada nas proximidades (Klinge, 1969; Takeuchi, 1961, 1962; Aubréville, 1961). Medíamos os grandes fragmentos (árvores e galhos caídos) durante a pesquisa, dentro de cada parcela, tirando amostras para análise química. Madeira morta em pé entrava no inventário.

Em 10 das 40 parcelas arrancamos as plantas superiores a $1,5 \mathrm{~m}$ de altura - tanto quanto possível - com raizes ou as extraimos à mão ou com o auxílio de uma alavanca, a fim de facilitar uma estimativa de massa radicular em relação com a determinação de massa radicular das covas. Nas parcelas restantes cortamos as plantas com facão, ma-

$(*) \rightarrow$ Pedólogo, Instituto Max-Planck de Limnologia, Depto. de Ecologia Tropical, Plön/Holstein, Alemanha.

(**) - Botânico, Instituto Nacional de Pesquisas da Amazônia, Centro de Pesquisas Florestais, Manaus, Amazonas. Bolsista do Conselho Nacional de Pes quisas. 
chado e uma serra mecânica portátil. Separamos as fôlhas dos raminhos e as raizes dos caules, pesamos estas 4 frações e tiramos algumas amostras para análise química.

Secávamos as amostras ao sol em nosso acampamento na mata tanto quanto a estação super-úmida de verão nos permitia, e as levávamos semanalmente para o laboratório do I.N.P.A. para completa secagem na estufa. Triturávamos com facão ou machado as amostras de raminhos, galhos, caules e raizes menores; serrávamos os galhos, raizes e troncos maiores e coletávamos a serragem. Depois de secas, embalamos as amostras e as enviamos ao laboratório do primeiro co-autor em Plön. - Em algumas parcelas não colhíamos individualmente as plantas menores, mas as agrupávamos em classes de igual comprimento total e/ou diâmetro de caule, tomando amostras dêsses grupos (fôlhas, ramos, caules, raizes).

Os cipós entravam no inventário apenas se tinham um diâmetro à altura do peito de cêrca de $10 \mathrm{~cm}$ ou mais; agrupávamos os cipós mais finos por parcela, pesávamos e tirávamos amostras como as árvores.

De tôdas as plantas superiores a $1,5 \mathrm{~m}$ de altura, coletávamos espécimes para herbário, inclusive amostras de madeira da maioria das árvores maiores.

No Qua,dro I damos o número ce árvores, palmeiras, cipós e madeira morta em pé e no Quadro II, o número de plantas menores de $1,5 \mathrm{~m}$ de altura. No Quadro III apresentamos os dados sôbre pêso de fôlhas, caule e galhos para as diferentes classes de altura e grupos de plantas separadamente. - Apresentaremos em trabalhos subsequentes os dados para raizes e matéria orgânica morta do ecossistema estudado (manta vegetal, matéria orgânica. do solo, madeira morta em pé, madeira morta à superfície do solo) .

Floristicamente, registramos 505 espécies de plantas superiores na área estudada pertencentes a 59 famílias.

Damos no Quadro IV as principais famílias pelo número de espécies e indivíduos respectivamente. Apenas 9 indivíduos pertencentes a 7 espécies não puderam ser determinados por família. Êsses dados estatísticos sâo parcialmente comparáveis a.os apresentados por Aubréville (1961), Cain \& Castro (1959) e Rodrigues $(1961,1963)$ para outras áreas amazônicas.

QUADRO I

Número de árvores, palmeiras, cipós e madeira morta em pé superiores a altura total de $1,5 \mathrm{~m}$.

\begin{tabular}{|c|c|c|c|c|c|}
\hline Faixa $n$ & Árvores & Palmeiras & Cipós & Madeira morta em pé & Total geral \\
\hline I & 188 & 28 & 7 & 2 & 225 \\
\hline II & 225 & 33 & 6 & 3 & 267 \\
\hline III & 187 & 23 & 7 & 3 & 220 \\
\hline IV & 215 & 26 & 7 & 4 & 252 \\
\hline $\mathrm{V}$ & 215 & 25 & 7 & 0 & 247 \\
\hline VI & 215 & 24 & 2 & 5 & 246 \\
\hline VII & 290 & 22 & 3 & 5 & 320 \\
\hline VIII & 272 & 15 & 2 & 3 & 292 \\
\hline Total $/ 2.000 \mathrm{~m}^{2}$ & 1807 & 196 & 41 & 25 & 2.069 \\
\hline por ha & 9.035 & 980 & 205 & 125 & 10.345 \\
\hline
\end{tabular}


QUADRO II

Número de plantas abaixo de $1,5 \mathrm{~m}$ de altura

\begin{tabular}{|c|c|c|c|c|c|}
\hline Parcela n $O$ & $<20$ & $20.50 \mathrm{~cm}$ & $50-100 \mathrm{~cm}$ & $100-150 \mathrm{~cm}$ & Total \\
\hline $\mathrm{I} a+b$ & 539 & 199 & 53 & 12 & 803 \\
\hline J c & 103 & 99 & 37 & 17 & 256 \\
\hline IV $\mathrm{d}$ & 248 & 120 & 61 & 24 & 453 \\
\hline IV e & 148 & 75 & 48 & 24 & 295 \\
\hline VI d & 104 & 109 & 64 & 65 & 342 \\
\hline VI $\mathrm{f}$ & 213 & 73 & 60 & 63 & 409 \\
\hline VII $c$ & 138 & 115 & 85 & 95 & 433 \\
\hline VII d & 138 & 66 & 95 & 58 & 357 \\
\hline Total $/ 2000 \mathrm{~m}^{2}$ & 8.155 & 4.280 & 2.515 & 1.790 & 16.740 \\
\hline por ha & 40.775 & 21.400 & 12.575 & 8.950 & 83.700 \\
\hline
\end{tabular}

Total de plantas vivas (contadas) por ha: 94.045

QUADRO III

Pêso de matéria fresca aérea por $2.000 \mathrm{~m}^{2}$ (por ha), em $\mathrm{Kg}$.

a) Plantas de altura acima de $1,5 \mathrm{~m}$

\begin{tabular}{cccccc}
\hline Forma biol. & Fôlhas & Caule & Galhos & Madeira, total & Total parcial \\
\hline \multirow{2}{*}{ Árvores } & $\begin{array}{c}3.212,2 \\
(16.061)\end{array}$ & $\begin{array}{c}101.416,95 \\
(507.085)\end{array}$ & $\begin{array}{c}43.101 \\
(215.505)\end{array}$ & $\begin{array}{c}144.517,95 \\
(722.590)\end{array}$ & $\begin{array}{c}147.730,2 \\
(738.651)\end{array}$ \\
\hline \multirow{2}{*}{ Palmeiras } & 705,8 & 389,8 & - & 389,8 & $1.095,6$ \\
& $(3.529)$ & $(1.949)$ & & $(1.949)$ & $(5.478)$ \\
\hline \multirow{2}{*}{ Cipós } & 209,9 & $8.959,9$ & & $8.959,9$ & $9.169,8$ \\
& $(1.050)$ & $(44.800)$ & & $(44.800)$ & $(45.850)$ \\
\hline \multirow{2}{*}{ Total geral } & $4.127,9$ & $110.766,65$ & 43.101 & $153.867,65$ & $157.995,6$ \\
& $(20.639)$ & $(553.833)$ & $(215.505)$ & $(769.338)$ & $(789.978)$ \\
\hline
\end{tabular}

b) Plantas de altura abaixo de $1,5 \mathrm{~m}$

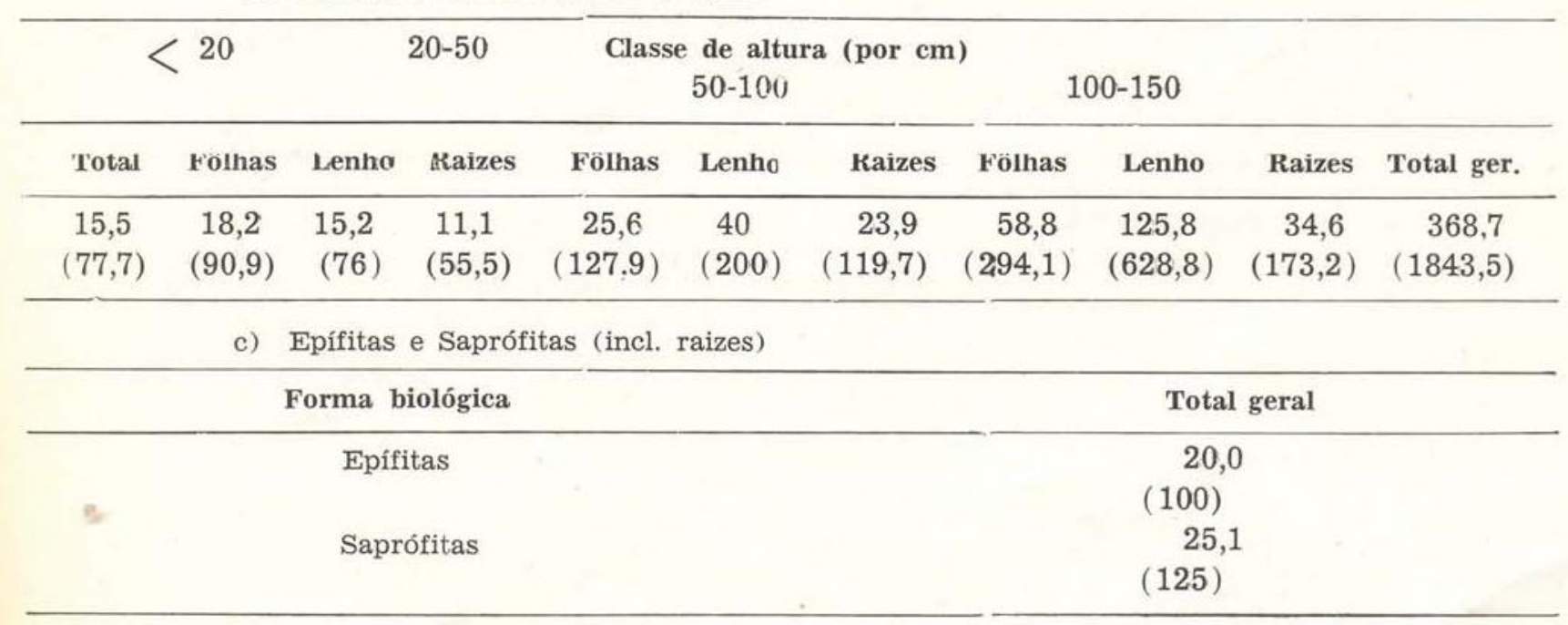




\section{QUADRO IV}

Principais familias pelo número de espécies e indiví. duos na mata de terra firme perto de Manaus, Amazonas, Brasil, levando em conta apenas as plantas superiores acima de $1,5 \mathrm{~m}$ de altura.

Familias principais $\begin{gathered}\text { Número } \\ \text { de espécies }\end{gathered} \quad \begin{gathered}\text { Número } \\ \text { de individuos }\end{gathered}$

\begin{tabular}{lrr} 
Leguminosae & 62 & 171 \\
Sapotaceae & 43 & 139 \\
Lauraceae & 40 & 88 \\
Chrysobalanaceae & 38 & 96 \\
Rubiaceae & 32 & 137 \\
Burseraceae & 27 & 230 \\
Annonaceae & 21 & 87 \\
Lecythidaceae & 17 & 129 \\
Moraceae & 17 & 69 \\
Palmae & 11 & 196 \\
Violaceae & 10 & 223 \\
48 familias menores & 180 & 412 \\
Indeterminadas & 7 & 9 \\
& & \\
\hline \multicolumn{1}{c}{ Tota $1:$} & 505 & 1.989 \\
\end{tabular}

\section{S U M M A R Y}

The procedure as used in sampling for quanti. tative and qualitative studies on litter is described in this first paper. Studies are being carried out in a "terra firme" forest in Central Amazonia. A botanical inventory of the area has proceded sampling.

\section{BIBLIOGRAFIA CITADA}

Altemüller, H. J. \& KLINGE, H.

1964 - Mikromorphologische Untersuchungen über die Entwicklung von Podsolen in Amazonasbecken. In: A. Jongerius (ed.). Soil Micromorphology. Amsterdam, Elsevier : 295-305.

Aubrévelille, A.

1761 - Etude écoloșique des principales formations végétales du Brésil. Nogent-sur-Marne, Centre Tecn. For. Trop., p. 1-2C.8.

Cain, S. A. \& Castro, G. M. de O.

1959 - Manual of vegetation analysis. New York, Ed. Harper \& Brothers, 325 p.
KLINGE, H.

1962 - Beitraege zur Kenntnis tropischer Böden. V. Z. Pflanzenernaehr., D ̈̈̈ng., Bodenkunde 97 (2) : 106-118.

1965 - Podzol soils in the Amazon basin. J. Soil Sci., 16 (1) : 95-103.

1967 - Podzol soils : a source of blackwater rivers in Amazonia. Atas Simpósio Biota Amazônica, (Limnologia) 3:117-125.

1969 - Review of research on tropical podzols. Report to FAO and UNESCO. $249 \mathrm{p}$.

KLINGE, H. \& OHLE, W.

1964 - Chemical properties of rivers in the Amazonian area in relation to soil conditions. Verh, int. Verein. Limnol., 15 (1) : 1067-1076.

KLINGE, H. \& ReDrigues, W. A.

1968 - Litter production in an area of Amazonian Terra firme forest. I. Amazoniana, 1 (4) : 303-310.

RODRIGUES, W. A.

1961 - Estudo preliminar de mata de várzea alta de uma ilha do baixo rio Negro de solo argiloso e úmido. Publi. INPA; Botânica, Manaus, $10: 1-50$

1961 - Aspectos fitossociológicos das catingas do rio Negro. Bol. Mus. Par. Emílio Goeldi; Nova série, Botânica, Belém, 15: 1-41.

1963 - Estudo de 2,6 hectares de mata de terra firme da Serra do Navio, Território do Amapá. Bol. Mus. Par. Emílio Goeldi; Nova Série; Botânica, Belém, $19: 1-22$.

1967 - Inventário florestal pilôto ao longo da estrada Manaus-Itacoatiara, Estado do Amazonas. Dados preliminares. Atas Simpósio Biota Amazônica. (Conservação da natureza e recursos naturais), $7: 257-267$.

SIOLI, H. \& KLINGE, H.

1962 - Solos, tipos de vegetação e águas na Amazônia. Bol. Mus. Par. Emílio Goeldi; Nova série; Avulsa, Belém, $1: 27-41$.

1966 - Anthropogene Vegetation am brasilianischen Amazonasgebiet. In R. Tüxen (ed) Anthropogene Vegetation. Junk, The Hague. p. 257-367.

TAKEUCHI, $M$,

1961 - The structure of the Amazonian vegetation. III. J. Fac. Sci, Univ. Tokyo, Sect. III, Bot., $8(1-3): 27-35$.

1962 - The structure of the Amazonian vegetation. IV. J. Fac. Sci. Univ. Tokyo, Sect. III, Bot., $s(4-7): 279-288$. 